\title{
How Social Media "Reverse Domesticate" and "Make the Best Use of Everything" from Students' Academic Achievement
}

\author{
Tianyu, gao $^{1 *}$ \\ ${ }^{1}$ Tianjin University, School for Education. Tianjin, China
}

\begin{abstract}
With the progress of science and technology, the development of social media websites is unprecedented. While changing people's communication way, it also brings certain influence to social life. At present, social media has become an essential part of students' daily life, and its academic impact on students depends on who uses it and how. In accordance with certain criteria, this paper searches the core database of Web of Science and obtains 17 and 11 independent samples respectively to study the correlation between the use of social media (entertainment or learning) and academic performance. The results show that: (1) the use of social media for learning is beneficial to improve students' academic performance, while the use for entertainment has a negative impact on academic performance; (2) the influence of social media use on students' academic achievement shows significant gender difference between the two groups. However, it did not change with students' country and survey time; (3) educational level only has a significant moderating effect on the correlation between social media (learning) and academic performance. Compared with middle school students, college students' academic.
\end{abstract}

\section{Introduction}

\subsection{Research background and problems}

The increasing popularity of the Internet is one of the most important social and cultural phenomena in the $21 \mathrm{st}$ century. With the increasing of the Internet's additional functions, people have adapted to it and seen how their lives have been changed. As far as students are concerned, the Internet has entered their lives in two ways: a universal ability of the syllabus and a new way for communicating. Social media, while changing people's way of social communication, also has a certain influence on life. Especially when it is integrated with mobile payment, it is difficult for students to reduce the use of social media applications.

Social Media refers to the platform, which help people to share opinions, experiences and views with each other [1]. In addition, using social media for academic activities has also become the main reason for most students. Studies have shown that modern technologies such as the Internet can help students solve problems in unknown fields and reduce dependence on teachers and classmates after class to realize lifelong learning [2]. According to an online survey of college students in Hong Kong, the use of social media is helpful for students to share, discuss and search information, but students are also easily distracted by the entertainment and social functions of social media [3]. In this paper, academic achievement refers to the results of individual academic performance, which is one of the important indicators to evaluate students' academic performance.

Studies have shown that academic achievement is affected by students' gender, age, education level, time spent on social media and other factors [4]. Moreover, most studies have verified a significant negative correlation between academic achievement and social media, but some studies have pointed out that there is no necessary correlation between them. In addition, individual characteristics such as gender and education level are important factors affect the social media use's consequences[5]. Then, do both the learning and recreational functions of social media have an impact on students' academic achievement? If so, to what extent? Does the effect vary from person to person? Vary by study design? This paper will take students' use of social media as the starting point to explore its effect on academic achievement under different functions, as well as whether there differences in sample or research methods.

\subsection{Theoretical basis and research hypothesis}

Social media gives individuals a new way to communicate with people anywhere, anytime and exchange ideas and information effectively[6]. College students mainly use social media to search resources and complete tasks assigned by teachers. Studies have found that using social media to conduct academic research can make students show higher participation and satisfaction [7]. The following hypotheses are proposed:

gaotianyu1223@163.com 
$\mathrm{H} 1$ :The LFSM1 ${ }^{1}$ is positively correlated with $\mathrm{AA}^{2}$.

Emerging entertainment functions, such as online games, short videos and online chats, make social media a tool for students to kill boring time, no matter having dinner, going to the toilet or taking a bus[8]. It can be seen that social media is characterized by fragmentation[9]. Studies show that the potential of Internet distraction exceeds its productive potential [10]. Some scholars have also found that students with poor academic achievements usually spend more time on leisure activities [11,12]. Therefore, the following hypotheses are proposed:

$\mathrm{H} 2$ :The $\mathrm{EFSM}^{3}$ was negatively correlated with AA.

Measurement is the application of research methods. Different measurements contain different contents, meanings and theoretical construction bases, which affect the correlation between variables [13]. At present, the measurement of academic achievement mainly includes tests' score and subjective scale. The former is obtained by the final score of related subjects (such as GPA), while the latter is mainly measured by the self-assessment. The use of social media is divided into two measurement methods: objective frequency and subjective scale. Since the subjective scale contains individual thoughts, it may affect the accuracy of the research results $[14,15,16]$. Therefore, the following hypotheses are proposed:

H1-1: Variable measures played a moderating role in the relationship between EFSM and AA;

$\mathrm{H} 2-1$ : Variable measures played a moderating role in the relationship between LFSM and AA;

The influence of social media on students' academic achievement is bi-directional. Males pay more attention to the positive parts of social media in relieving emotions or satisfying needs, and use it to collect information and optimize learning time management, while females pay more attention to the negative parts, such as wasting time[17,18]. Boys often use social media's learning function to assist their academic research. Girls are more addicted to the novel experience brought by the entertainment functions, and boys are more inclined to chat when they encounter difficulties [Wang Yanming]. Therefore, relevant hypotheses are proposed:

H1-2: Compared with women, male use of EFSM has a greater negative impact on AA;

H2-2: Compared with women, men's use of LFSM has a stronger positive effect on AA;

From the perspective of education level, middle school students are still in adolescence, and their mind is not mature [20]. When they use the EFSM, they are easy to be bound by mixed information and fall into the dilemma of social media dependence[21]. Compared with other groups, college students are the most active and extensive group with access to social media, and most of them are adults. College students have more free time to study in other places, and the versatility of emerging social media can meet the needs of college students studying in other places in life and study [8]. It can be seen that college students can better use social media as a tool to assist their life and study. The following hypotheses are proposed:
H1-3: Compared with adults, teenagers' use of EFSM has a greater negative effect on their AA;

H2-3: Compared with adults, teenagers' use of LFSM has a weak promotion effect on their AA;

Different regions have differences in economy, politics, culture, which will affect students' motivations and habits of using social media [22]. From the macro perspective, mainly reflected in the difference between individualism and collectivism. In collectivist culture (e.g., East Asian countries), people value harmonious coexistence with a group and becoming a member of it, while in individualistic culture (e.g., European and American countries), people are more inclined to be individual [23]. Therefore, the following hypotheses are proposed:

H1-4: Regional distribution plays a moderating role in the relationship between EFSM and AA;

$\mathrm{H} 2-4$ : Regional distribution plays a moderating role in the relationship between LFSM and AA;

The survey time can not only reveal the development trend of the relationship between the two factors, but also reveal the changing network environment [24]. The rapid development of the Internet to promote constantly update and perfect the function of social media, for example, online courses, take photos for answers, the piano online partners provides convenient for student's extracurricular life. At the same time, social media related entertainment function,such as fine quality, rich storyline, regularly distributed gifts, will make students more easily. The hypotheses are proposed:

H1-5: With the development of The Times, EFSM has a greater negative impact on AA;

H2-5: With the development of The Times, LFSM has a stronger positive impact on AA.

Sample size is an important part of investigation. Previous studies believe that the larger the sample size is, the more comprehensive the overall characteristics are, and the higher the accuracy of the research results will be. However, the larger the sample size is, the higher the cost will be. The hypothesis are proposed:

H1-6: Sample size plays a moderating role in the relationship between EFSM and AA;

H2-6: Sample size plays a moderating role in the relationship between LFSM and AA.

\section{Methodology -- Meta-analysis}

\subsection{Literature screening}

Through the core collection of the Chinese database CNKI and the foreign language database Web of Science (including SCI-Expand, SSCI, A\&HCI, CPCI-S, and ESCI), With "academic achievement", "academic outcome", "school outcome", "school achievement", "grade", "score", "social media", "social network site", "social media", "academic achievement" and "achievement" as key words without limitation of time range. Literature inclusion criteria: (1)literature involved

\footnotetext{
1 LFSM:Learning function of social media.

2 AA:Academic achievement.

3 EFSM:Entertainment function of social media.
} 
an empirical study on the relationship between the use of social media (recreational function or learning function) and academic achievement, and the data was complete; (2)the research object is students; (3)explaining the measurement method of social media use achievement for specific functions; (4)review literature, republished literature and data error literature were excluded. After screening, a total of 18 papers (EFSM) and 16 papers(LFSM) were initially retrieved.

\subsection{Data extraction}

The meta-analysis consists of two tasks: understanding the combined effect of an intervention and exploring the factors that influence the outcome of an intervention. There are two ways to select moderators: (1) according to the existing meta-analysis literature, the frequency statistics of moderators or related topic research conclusions are carried out; (2)selected from professional and statistical perspectives. Based on the above approaches and the purpose of this study, the following moderating variables were selected in this paper: gender, education level, survey area, measurement method and survey time.

When there are multiple data on the effect value of the relationship between social media and academic achievement in the same literature, the selection of effect value follows the priority principle of "correlation coefficient, regression coefficient and path coefficient", and the range of regression coefficient or path coefficient should be between -0.5 and 0.5 . According to the above criteria, a total of 14 articles were finally included in recreational functional meta-analysis and 14 articles were included in learning functional meta-analysis. The path coefficient and regression coefficient refer to Peterson and
Brown (2005) : $\mathrm{r}=\beta^{*} 0.98+0.05(\beta \geq 0) ; \mathrm{R}=\beta^{*} 0.98-0.05(\beta<$ 0) $(\beta \in(-0.5,0.5))$ for transformation.

\subsection{Document coding}

When exploring a moderating variable of a main effect, literature information containing this factor should be screened out, and at least 5 papers should be taken as the lower limit for the number of studies in the meta-analysis. Therefore, on this basis, the common demographic characteristics of each study were searched and coded.

\section{Research conclusion}

\subsection{Heterogeneity of effect value and test of main effect}

Heterogeneity test is to measure the level of heterogeneity between different study effect values. The results of this study show that different functions of social media have significant correlation and heterogeneity with academic achievement (Table1), indicating that there is heterogeneity among different studies. Based on the heterogeneity test results of each effect value, this study used a random effect model to test the correlation between the use of different functions of social media and academic achievement.

Meta-analysis results show that the use of social media entertainment function would have a significantly negative effect on academic achievement ( $p<0.001)$, but if will social media study function would have a significantly positive effect on their learning achievements $(\mathrm{p}<0.001)$, assuming the $\mathrm{H} 1$ and $\mathrm{H} 2$.

Table1. Test of main effect

\begin{tabular}{|c|c|c|c|c|c|c|c|c|c|c|c|c|}
\hline \multirow{2}{*}{$\begin{array}{c}\text { The } \\
\text { main } \\
\text { effect }\end{array}$} & \multirow{2}{*}{$\begin{array}{l}\text { Number } \\
\text { studies }\end{array}$} & \multirow{2}{*}{$\underset{\text { size }}{\text { Sample }}$} & \multirow{2}{*}{$\begin{array}{l}\text { Effect } \\
\text { size }\end{array}$} & \multicolumn{2}{|c|}{ two-tailed test } & \multicolumn{2}{|c|}{$\mathbf{9 5 \%}$ interval } & \multicolumn{2}{|c|}{ heterogeneity } & \multirow{2}{*}{\begin{tabular}{|l}
$\begin{array}{l}\text { Fail-safe } \\
\text { number }\end{array}$ \\
$N f s, 0.05$ \\
\end{tabular}} & \multicolumn{2}{|c|}{$\begin{array}{c}\text { Egger's Regression } \\
\text { intercept }\end{array}$} \\
\hline & & & & $\begin{array}{c}Z- \\
\text { value }\end{array}$ & $\begin{array}{c}P \text { - } \\
\text { value }\end{array}$ & $\begin{array}{c}\text { Upper } \\
\text { limit }\end{array}$ & $\begin{array}{c}\text { Lower } \\
\text { limit }\end{array}$ & $Q$-value & $\begin{array}{c}I- \\
\text { squared }\end{array}$ & & Intercept & P-value \\
\hline EFSM & 18 & 20289 & -0.089 & $12 . \overline{7} 45$ & 0.000 & -0.076 & -0.103 & 146.903 & 88.428 & 403 & 0.76081 & 0.55056 \\
\hline LFSM & 14 & 16848 & 0.139 & 18.164 & 0.000 & 0.154 & 0.124 & 113.076 & 88.503 & 935 & 1.18476 & 0.38859 \\
\hline
\end{tabular}

\subsection{The moderating effect of social media on academic achievement}

\subsubsection{Test of the moderating effect of EFSM and AA}

The correlation of EFSM and AA is significantly affected by social media's measurement, gender, survey time, sample size, but the correlation has nothing to do with age or regional distribution, so the H1-1, H1-2, H1-5, H1-6 is accepted, the H1-3, H1-4 was rejected.

Table2. Test of the moderating effect of EFSM and AA

\begin{tabular}{|c|c|c|c|c|c|c|c|c|c|c|}
\hline \multirow{2}{*}{$\begin{array}{l}\text { Moderating } \\
\text { variable }\end{array}$} & \multirow[b]{2}{*}{ category } & \multirow{2}{*}{$\begin{array}{l}\text { Number } \\
\text { studies }\end{array}$} & \multirow{2}{*}{$\begin{array}{l}\text { Effect } \\
\text { size }\end{array}$} & \multicolumn{2}{|c|}{ Test of null(2-Tail) } & \multicolumn{2}{|c|}{$95 \%$ interval } & \multicolumn{3}{|c|}{ Differences between groups } \\
\hline & & & & Z-value & $P$-value & $\begin{array}{c}\text { Upper } \\
\text { limit }\end{array}$ & $\begin{array}{c}\text { Lower } \\
\text { limit }\end{array}$ & $Q$-value & $d f(Q)$ & $P$-value \\
\hline \multirow{2}{*}{$\begin{array}{c}\text { Variable } \\
\text { measurement } \\
\text { (social media) }\end{array}$} & $\begin{array}{l}\text { Objective } \\
\text { use } \\
\text { frequency }\end{array}$ & 15 & -0.086 & -11.936 & 0.000 & -0.072 & -0.100 & \multirow[t]{2}{*}{4.991} & \multirow[t]{2}{*}{1} & \multirow[t]{2}{*}{0.025} \\
\hline & $\begin{array}{l}\text { Subjective } \\
\text { scale }\end{array}$ & 3 & -0.158 & -4.995 & 0.000 & -0.096 & -0.218 & & & \\
\hline
\end{tabular}




\begin{tabular}{|c|c|c|c|c|c|c|c|c|c|c|}
\hline \multirow{2}{*}{ gender } & $\begin{array}{c}\text { Proportion } \\
\text { of male }< \\
0.4\end{array}$ & 8 & -0.110 & -10.532 & 0.000 & -0.090 & -0.130 & \multirow{2}{*}{3.102} & \multirow{2}{*}{1} & \multirow{2}{*}{0.078} \\
\hline & $\begin{array}{c}\text { Proportion } \\
\text { of male }> \\
0.4\end{array}$ & 6 & -0.085 & -8.303 & 0.000 & -0.065 & -0.104 & & & \\
\hline \multirow{2}{*}{ Age } & teenagers & 5 & -0.088 & -8.171 & 0.000 & -0.067 & -0.108 & \multirow{2}{*}{0.420} & \multirow{2}{*}{1} & \multirow{2}{*}{0.517} \\
\hline & adults & 11 & -0.097 & -9.285 & 0.000 & -0.077 & -0.118 & & & \\
\hline \multirow[b]{2}{*}{$\begin{array}{l}\text { Regional } \\
\text { distribution }\end{array}$} & $\begin{array}{c}\text { East Asian } \\
\text { countries }\end{array}$ & 8 & -0.092 & -8.465 & 0.000 & -0.071 & -0.113 & \multirow[b]{2}{*}{0.390} & \multirow[b]{2}{*}{1} & \multirow[b]{2}{*}{0.532} \\
\hline & $\begin{array}{c}\text { European } \\
\text { and } \\
\text { American } \\
\text { countries }\end{array}$ & 9 & -0.083 & -8.668 & 0.000 & -0.064 & -0.102 & & & \\
\hline \multirow{2}{*}{ Survey time } & Before 2017 & 9 & -0.097 & -12.603 & 0.000 & -0.082 & -0.112 & \multirow{2}{*}{5.852} & \multirow{2}{*}{1} & \multirow{2}{*}{0.016} \\
\hline & After 2017 & 9 & -0.052 & -3.074 & 0.002 & -0.019 & -0.085 & & & \\
\hline \multirow{2}{*}{ Sample size } & $<1000$ & 13 & -0.065 & -4.411 & 0.000 & -0.036 & -0.094 & \multirow{2}{*}{3.462} & \multirow{2}{*}{1} & \multirow{2}{*}{0.063} \\
\hline & $>1000$ & 5 & -0.096 & -12.101 & 0.000 & -0.081 & -0.112 & & & \\
\hline
\end{tabular}

\subsubsection{Test of the moderating effect of LFSM and AA}

by academic achievement's measurement, gender, The correlation of LFSM and AA is significantly affected regional distribution, survey time, sample size, but it did not matter how social media was measured or age, so H22, H2-4, H2-5, H2-6 is accepted, H2-3 was refused, H2 -1 partly accepted.

Table3. Test of the moderating effect of LFSM and AA

\begin{tabular}{|c|c|c|c|c|c|c|c|c|c|c|}
\hline \multirow{2}{*}{$\begin{array}{l}\text { Moderating } \\
\text { variable }\end{array}$} & \multirow{2}{*}{ category } & \multirow{2}{*}{$\begin{array}{l}\text { Number } \\
\text { studies }\end{array}$} & \multirow{2}{*}{$\begin{array}{c}\text { Effect } \\
\text { size }\end{array}$} & \multicolumn{2}{|c|}{$\begin{array}{c}\text { Test of null(2- } \\
\text { Tail) }\end{array}$} & \multicolumn{2}{|c|}{$95 \%$ interval } & \multicolumn{3}{|c|}{$\begin{array}{c}\text { Differences between } \\
\text { groups }\end{array}$} \\
\hline & & & & Z-value & $\begin{array}{c}P- \\
\text { value }\end{array}$ & $\begin{array}{c}\text { Upper } \\
\text { limit }\end{array}$ & $\begin{array}{c}\text { Lower } \\
\text { limit }\end{array}$ & $\underset{\text { value }}{Q-}$ & $d f(Q)$ & $\begin{array}{c}P- \\
\text { value }\end{array}$ \\
\hline \multirow{4}{*}{$\begin{array}{c}\text { Variable } \\
\text { measurement } \\
\text { (social media) } \\
\text { Variable } \\
\text { measurement } \\
\text { (academic } \\
\text { achievement) }\end{array}$} & $\begin{array}{l}\text { Objective use } \\
\text { frequency }\end{array}$ & 7 & 0.137 & 16.553 & 0.000 & 0.153 & 0.121 & \multirow{3}{*}{0.530} & \multirow[t]{3}{*}{1} & \multirow{3}{*}{0.467} \\
\hline & Subjective scale & 7 & 0.153 & 7.514 & 0.000 & 0.192 & 0.113 & & & \\
\hline & Tests' scores & 11 & 0.131 & 16.441 & 0.000 & 0.146 & 0.115 & & & \\
\hline & Subjective Scale & 3 & 0.257 & 8.817 & 0.000 & 0.310 & 0.201 & 18.100 & 1 & 0.000 \\
\hline \multirow{2}{*}{ Gender } & $\begin{array}{c}\text { Proportion of male }< \\
0.5\end{array}$ & 8 & 0.125 & 14.948 & 0.000 & 0.141 & 0.109 & \multirow{2}{*}{21.156} & \multirow{2}{*}{1} & \multirow{2}{*}{0.000} \\
\hline & $\begin{array}{c}\text { Proportion of male }> \\
0.5\end{array}$ & 5 & 0.227 & 10.829 & 0.000 & 0.266 & 0.187 & & & \\
\hline Age & $\begin{array}{c}\text { teenagers } \\
\text { adults }\end{array}$ & $\begin{array}{l}3 \\
8\end{array}$ & $\begin{array}{l}0.120 \\
0.123\end{array}$ & $\begin{array}{c}5.835 \\
10.212\end{array}$ & $\begin{array}{l}0.000 \\
0.000\end{array}$ & $\begin{array}{l}0.160 \\
0.146\end{array}$ & $\begin{array}{l}0.080 \\
0.099\end{array}$ & 0.009 & 1 & 0.924 \\
\hline \multirow[b]{2}{*}{$\begin{array}{l}\text { Regional } \\
\text { distribution }\end{array}$} & East Asian countries & 7 & 0.174 & 9.448 & 0.000 & 0.209 & 0.138 & \multirow[b]{2}{*}{5.843} & \multirow[b]{2}{*}{1} & \multirow[b]{2}{*}{0.016} \\
\hline & $\begin{array}{c}\text { European and } \\
\text { American countries }\end{array}$ & 5 & 0.125 & 14.518 & 0.000 & 0.142 & 0.109 & & & \\
\hline Survey time & $\begin{array}{c}\text { Before } 2017 \\
\text { After } 2017\end{array}$ & $\begin{array}{l}5 \\
9\end{array}$ & $\begin{array}{l}0.131 \\
0.161\end{array}$ & $\begin{array}{l}14.632 \\
10.909\end{array}$ & $\begin{array}{l}0.000 \\
0.000\end{array}$ & $\begin{array}{l}0.148 \\
0.190\end{array}$ & $\begin{array}{l}0.114 \\
0.133\end{array}$ & 3.154 & 1 & 0.076 \\
\hline Sample size & $\begin{array}{l}<1000 \\
>1000\end{array}$ & $\begin{array}{c}11 \\
3\end{array}$ & $\begin{array}{l}0.196 \\
0.122\end{array}$ & $\begin{array}{l}12.428 \\
13.887\end{array}$ & $\begin{array}{l}0.000 \\
0.000\end{array}$ & $\begin{array}{l}0.226 \\
0.139\end{array}$ & $\begin{array}{l}0.166 \\
0.105\end{array}$ & 17.375 & 1 & 0.000 \\
\hline
\end{tabular}

\section{Conclusion}

\subsection{The relationship between social media use and academic achievement}

(1)The EFSM has a negative impact on AA; (2)the LFSM helps to improve AA. With the development of media technology, social media has advantages such as real-time communication and diversified forms of information transmission, which naturally integrates into students' study and life. The LFSM can enrich the learning forms, increase the communication among students, thus promoting the academic progress. In terms of EFSM, the mass information and diversified functions brought by social media usually make students unable to deal with redundant information. The above behavior will make students increase the useless time spent on social media, and even escape from social media[25].

\subsection{Moderating effect of variable measures}

The moderating effect of variable measurements on the correlation between social media and academic achievement is complex, which may be the reason for the divergent results of previous studies. In terms of the EFSM, compared with the frequency, the correlation is stronger which measured by the subjective scale. In terms of LESM, the moderating effect of social media measurement was not significant, but the moderating effect of academic achievement's measurement was significant. Specifically, academic achievement measured by the subjective scale has a higher correlation. This may be due to the fact that the the subjective scale can capture different aspects of 
complex constructs and thus achieve higher correlations [26]. Due to developing of technological innovation,it is difficult to distinguish various types of media[27]. In addition, since most of the data are self-reported, the situation of false information or students' inability to accurately evaluate themselves cannot be excluded [2].

\subsection{Moderating effect of demographic factors}

According to the results of moderating effect test, no matter whether students are adults or not, their use of social media has no significant difference in the influence on academic achievement. However, there are also certain boundary conditions for the influence, mainly reflected in the moderating effect of variables such as measurements, gender, survey time, sample size and other factors. The specific conclusions are as follows:

Gender played a moderating role in the relationship. Boys' use of LFSM had greater benefits on their AA, and EFSM had less harm. This moderating effect may be due to gender differences in motivation of use. Women use social media to communicate with peers, while men use social media to compensate for the satisfaction of socializing, learning and obtaining social identity [28]. In particular, nowadays most college students are used to relying on mobile devices for learning and entertainment. Due to the large number of female students who engage in social chatting with their motivation, they are highly dependent on social media and are more susceptible to the influence of conformity psychology and behavior [29]. Studies have shown that male students have more advantages in self-efficacy, learning control and learning management when conducting online independent learning [30].

The correlation between SMLF and AA was only significantly moderated by group geography. In other words, students in East Asian countries can make better use of the advantages of social media in resource sharing, mobile convenience, personalized learning and other aspects to assist their studies. However, group geography did not significantly regulate the correlation between social media recreational function and academic achievement. This may be because the open network, as a worldwide cultural and information exchange center, has the advantages of pluralism, immediacy and interaction without spatial differences [31]. The differences in different countries only make teenagers choose different types of social media. Social media aims to better combine the youth of different countries in the world and form social groups in the virtual world [32]. Therefore, social media is a global problem to some extent, but not a national one.

The survey time positively moderated the relationship. The more recently surveyed literature was published, the negative effect of EFSM on AA weakened, while the promoting effect of LFSM increased. This may be because various functions of social media have gradually developed and improved, especially in user privacy and teenagers' protection. However, it does not exclude that the time span of the literature selected in this metaanalysis is small[33]. In terms of sample size, the absolute value of effect size in large sample studies is smaller than that of small sample studies, and it is closer to the combined effect size. It can be inferred that increasing the sample size can reduce the error of research results and thus more accurately assess the impact of social media on academic achievement.

\subsection{Suggestions}

\subsubsection{Pay attention to the negative effect of information overload in social media on students' academic performance}

Most social media still have some disadvantages in the information search function. Students have to passively accept all the information published by netizens. Although useless information can be blocked by keyword search, the degree of personalization is poor. For example, the fields and depth of attention of different users on the same topic will be different. Therefore, users need to spend a lot of time and energy in the mass of information to find useful content, which increases the cost of acquiring knowledge. In addition, some social networking sites contain a lot of advertising and spam information, which pollutes the network environment, especially for underage primary and secondary school students, which will increase their psychological pressure and even endanger their physical health. Therefore, social media should be based on personalized recommendation mechanism to achieve functional modular design, so that users can quickly find the information they need in a short time [34].

\subsubsection{Explore the impact of different groups on academic achievement when using social media}

Regardless of the entertainment function or learning function of social media, the relationship between social media and learning is gender heterogeneity. Some scholars believe that this may be due to gender differences in the acceptance of new social media functions [35].At the same time, there are differences in the patterns of using social media between boys and girls. Women tend to connect with old friends and share their lives, while men like to kill time and establish new relationships [36]. In addition, students from different countries have different influences on their studies when they use the learning function of social media. Students in different regions have different preferences for learning function of social media due to different educational goals and training systems. Research shows that students are more likely to use localized social media tools. Therefore, it is necessary to optimize the relevant functions of social media according to the learning habits and learning styles of students in different regions.

\subsubsection{Future research direction of improving the relationship between social media and academic achievement}

The results show that the measurement of variables, 
sample size and survey time will have a significant impact on the survey results. The measurement methods of variables include subjective scale measurement and objective actual data. The sample size is divided into large sample size of more than 1000 people and small sample size of less than 1000 people. The results show that the relationship between social media and academic achievement measured by the objective scale is stronger whether it is entertainment function or learning function. The advantages of different measurement methods are different. The multi-dimensional measurement of subjective scale can measure variables more comprehensively, but it is easy to be interfered by the subjective factors of the subjects. Although the objective actual data is true, it may lead to the deviation of the results because it is too one-sided. Therefore, future research should pay more attention to whether the characteristics of survey samples and differences in research design will have a significant impact on the relationship between the two.

\section{REFERENCES}

1. Tan Xinbin, Luo Jianhe. A review on the use of social media by foreign college students $[\mathrm{J}]$. Education academic monthly,2018(07):78-85.

2. Shen, J. 2019. Social-media use and academic performance among undergraduates in biology. Biochemistry and Molecular Biology Education.

3. Li Huating, Wang Wei, Wang Wenting. The impact of the use of social media and its multitasking on College Students' academic achievement [J]. Journal of Hubei University of Economics (HUMANITIES AND SOCIAL SCIENCES),2018,15(10):128-131.

4. Jomon Aliyas Paul, Hope M. Baker, Justin Daniel Cochran. 2012. Effect of online social networking on student academic performance. Computers in Human Behavior.

5. Hatice Yildiz, Suleyman Sadi Seferoglu. 2020. Antecedents of Social Media Usage Status Examination of Predictiveness of Digital Literacy, Academic Performance, and Fear of Missing Out Variables. Social Science Quarterly.

6. Yvonne Hong, Lesley Gardner. 2018. Undergraduates' perception and engagement in Facebook learning groups. British Journal of Educational Technology.

7. Li Dongsheng, Xin Ying, Wei Le. The negative influence of mobile social media on college students and the countermeasures [J]. Journal of Jilin Institute of education,2015,31(05):136-137.

8. Wang Jie. The influence of new social media on College Students' behavior and its causes [J]. Journal of Hubei correspondence university,2017,30(07):1516.

9. Yi Lin. the influence of new media on contemporary college students in the micro era $[\mathrm{J}]$. Science and technology communication,2015,7(08):115-116.

10. Derbyshire, K. L., Lust, K. A., Schreiber, L. R. N.,
Odlaug, B. L., Christenson, G. A., Golden, D. J., et al. 2013. Problematic internet use and associated risks in a college sample. Comprehensive Psychiatry, Vol. 54.

11. Chen, S. Y., Fu, Y. 2009. Internet use and academic achievement: gender differences in early adolescence. Adolescence, Vol. 44.

12. Derbyshire, K. L., Lust, K. A., Schreiber, L. R. N., Odlaug, B. L., Christenson, G. A., Golden, D. J., et al. 2013. Problematic internet use and associated risks in a college sample. Comprehensive Psychiatr.

13. Ding Fengqin, Zhao Huying. Is gratitude stronger for individual subjective well-being? -- a meta-analysis [J]. Advances in psychological science, 2018, 26(10): 1749-1764.

14. Huiyoung Shin,Allison M. Ryan. 2014. Friendship Networks and Achievement Goals: An Examination of Selection and Influence Processes and Variations by Gender. Journal of Youth and Adolescence, Vol. 9.

15. Allison M. Ryan. 2000. Peer Groups as a Context for the Socialization of Adolescents' Motivation, Engagement, and Achievement in School. Educational Psychologis, Vol. 2.

16. Sha Jingying, Zhang Xiangkui, Deng Xiaoping. Meta analysis on the homogeneity of academic achievement between adolescents and their peer groups [J]. Applied psychology,2017,23(04):345-354.

17. Zheng Junjun, Liu Chunyan, Shen Xiaoliang, Shao Cong. Research on social media user participation based on use and satisfaction theory -- considering the mediating role of problem use and the moderating role of gender [J]. Technical economy,2017,36(01):123129.

18. Zhang Zhisong, Li Fuhua. Investigation on Internet Addiction of college students [J]. Research on teacher education,2011,23(02):44-48.

19. Wang Yanming, Wang Yingying. Investigation on gender differences and Internet purposes of college students with internet addiction [J]. Journal of Heilongjiang University of education, 2015, 34(09): 107-108.

20. Feng Li. Investigation report on media literacy of middle school students -- taking high schools in Jiangsu, Gansu and Henan as examples [J]. Communication and copyright,2014(11):122$123+125$.

21. Liu Tianyuan. Analysis of the impact of social media on the academic performance of rural teenagers -Taking the experience of $\mathrm{X}$ village in Guanzhong Plain as an example [J]. China Youth Research,2018(09):70-77+30.

22. Wu Shengtao, Zhou Yang, Fu Xiaolan, Liu Xiaoqian, Liu Tianli, Zhu Tingshao. The cultural and cooperative communication pattern along the "one belt along the way": Based on the psychological analysis of big data in social media [J]. China Academy of Sciences,2018,33(03):298-307.

23. Oyserman Daphna,Coon Heather M,Kemmelmeier Markus. 2002. Rethinking individualism and 
collectivism: evaluation of theoretical assumptions and meta-analyses. Psychological Bulletin.

24. Jiang Jianhua, Liu Chengjun, Jiang Tianying. Meta analysis of the relationship between organizational learning and organizational performance: Based on the moderating effect of measurement factors and situational factors $[\mathrm{J}]$. Scientific research management,2014,35(08):117-125.

25. Tian ran. Research on the influence of information overload on wechat user behavior acculturation [D]. University of Electronic Science and technology, 2020.

26. Churchill Gilbert A. 1979. A paradigm for developing better measures of marketing constructs. Journal of Marketing.

27. Wade C., Jacobsen, B.S., and Renata Forste, Ph.D. 2011. The Wired Generation: Academic and Social Outcomes of Electronic Media Use Among University Students. Cyberpsychology. Behavior and Social Networking, Vol. 14.

28. Barker V. 2009. Older adolescents' motivations for social network site use:The influence of gender,group identity, and collective self-esteem. Cyber Psychology Behavior, Vol 12.

29. Qu Lixin, Liu fengjuan. Research on mobile terminal use and classroom learning preference based on gender differences -- Taking the results of College Students' online questionnaire as an example [J]. Financial theory and teaching,2018(06):81-84.

30. Song Xianwen. Investigation and analysis of gender differences in college students' Online Autonomous Learning $[\mathrm{J}]$. Education and teaching forum,2014(02):172-173.

31. YAN Dan. Research on the characteristics of College Students' network behavior and education guidance [D]. Chang'an University,2009.

32. Li Wei, Xu Lingling. Comparison of youth social media applications between China and the United States [J]. People's forum,2015(36):244-246.

33. Guo Ying, he Xiangcai. The relationship between social support and mobile phone dependence of college students: a meta-analysis based on Chinese samples [J]. Journal of Sichuan Normal University (SOCIAL SCIENCE EDITION),2017,44(06):91-101.

34. Wang $\mathrm{Na}$, Ren ting. Research on information overload and personalized recommendation mechanism in mobile social networking sites [J]. Intelligence magazine,2015,34(08):190-194+176.

35. Li Yuanwen. Characteristics and relationship between peer attachment and loneliness of Internet and mobile phone addicted adolescents [D]. Central China Normal University,2013.

36. Bi Xiangyang. Gender differences in Internet addiction among college students: analysis of multiple mediating effects based on Internet use preference [J]. Xuehai,2016(04):134-142. 